\title{
Study on bulk current injection (BCI) evaluation method of battery pack
}

\author{
Bing Zhao ${ }^{1, a}$, Xin Liu ${ }^{1, b}$, Guangyu Zhang ${ }^{1, c, ~ *}$ and Yun Wang,d \\ ${ }^{1}$ China automotive technology and research center, Tianjin 300000, China; \\ ${ }^{2}$ School of mechanical engineering, Hebei University of Technology, Tianjin 300000, China; \\ a zhaobing @catarc.ac.cn, bliuxin1967@ catarc.ac.cn, ${ }^{\mathrm{c}}$ \\ zhangguangyu@catarc.ac.cn, ${ }^{\mathrm{d}} 15922080567 @ 163 . c o m$
}

Keywords: BCI, immunity, battery pack.

\begin{abstract}
Bulk current injection (BCI) is a method of carrying out immunity tests by inducing disturbance signals directly into the wiring harness by means of a current injection probe. In this paper, BCI method of domestic famous battery pack manufacturers is compared and studied. Based on the existing experiments, a new method for evaluation of BCI test is proposed.
\end{abstract}

\section{Introduction}

In recent years, as the rapid development of new energy vehicles, automotive electromagnetic compatibility issues become more and more important. Battery pack as one of the key components of new energy vehicles, Its electromagnetic compatibility can not be ignored. The battery pack typically includes a battery module and a battery management system(BMS).BMS can detect the battery status, estimate state of charge of power battery pack and so on. To ensure traffic safety, its immunity performance must be considerate. Bulk current injection method has been widely used for its Convenient layout and low cost and it can be tested in electromagnetic shielding room..

Bulk current injection (BCI) is a method of carrying out immunity tests by inducing disturbance signals directly into the wiring harness by means of a current injection probe[1]. The injection probe is a current transformer through which the wiring harnesses of the device under test (DUT) are passed. Immunity tests are carried out by varying the test severity level and frequency of the induced disturbance. Currently, the battery pack manufacturer's reference standard for BCI test for BMS or battery pack is mainly concentrated in 17619-1998 or the 2005 and 2011 editions of 11452-4.Because of the low severity level of 17619, it can not conform to the trend of the times.And the standard of ISO 11452-4 is gradually become the mainstream of reference for its fast version update.This paper summarizes the battery pack test standard of some well-known domestic manufacturers, so that domestic counterparts can learn from each other, thus promoting the technological progress of the industry. On the basis of this, a new method for testing the immunity performance of battery pack is presented.

\section{Research on Enterprise Standards}

In this paper, BCI method of domestic well-konwn battery pack manufacturers is compared and studied on wire length, immunity injection location, test frequency, test method, test severity grade,sample working state and so on.For manufacturers' confidentiality requirements, the name of enterprises is replaced by A,B,C,D and E.

\subsection{Wire Harness Length and Immunity Injection Location}

The length of the wire and the injection position will have a certain effect on the test result, company A specified that the length of the wire harness length of the sample to the load simulator was 
2000mm, while company B and C clearly require the length was $1700 \mathrm{~mm}(+300 / 0 \mathrm{~mm})$, and the other two demand that the layout should refer to the satand of ISO11452-4.

In terms of immunity injection position,only company E indicated that the current injection probe should be placed on the location of $450 \mathrm{~mm}$, and the others point out the test need to be carried out on three locations:150mm,450mm and $750 \mathrm{~mm}$.

\subsection{Test Frequency Band and Test Method}

Some manufacturers clearly pointed out that the use of substitution methods, and some claim that closed-loop method or substitution method are Optional[2].

Company A, D and E require that all low-voltage wire bundles be clamped within the injection probe, while conpany B and C come up with two injection Modes: Differential bulk current injection (DBCI) and common mode bulk current injection.( DBCI:The negative power line should be placed outside the BCI probe, and the rest of the lines should be placed inside the probe.CBCI: all low-voltage wire bundles should be clamped within the injection probe)

Table 1 Three Scheme comparing

\begin{tabular}{|c|c|c|}
\hline Frequency Band $(\mathrm{MHz})$ & Method & Location \\
\hline $0.1 \sim 15$ & DBCI & $150 \mathrm{~mm}, 450 \mathrm{~mm}$ \\
\hline $15 \sim 30$ & DBCI,CBCI & $150 \mathrm{~mm}, 450 \mathrm{~mm}$ \\
\hline $30 \sim 400$ & CBCI & $450 \mathrm{~mm}, 750 \mathrm{~mm}$ \\
\hline
\end{tabular}

\subsection{Test Severity Level}

There are four different test severity levels in ISO 11452-4:2005[1], they are 25mA, 50mA, $75 \mathrm{~mA}, 100 \mathrm{~mA}$. These four levels are relatively low compared to the vehicle factory standard, and only one manufacturer has chosen the severe grade of $75 \mathrm{~mA}$ for testing. The TEST severity level of other four manufacturers are listed in different frequency bands as shown in table 2

Table 2 test severity of different company in different frequency bands

\begin{tabular}{|c|c|c|c|c|}
\hline Frequency Band $(\mathrm{MHz})$ & $\mathrm{A}(\mathrm{mA})$ & $\mathrm{B}(\mathrm{mA})$ & $\mathrm{C}(\mathrm{mA})$ & $\mathrm{D}(\mathrm{mA})$ \\
\hline $0.1-1$ & - & $32-3.2$ & $32-3.2$ & - \\
\hline $1-15$ & 150 & $3.2-200$ & $3.2-200$ & 100 \\
\hline $15-30$ & 150 & 200 & 200 & 100 \\
\hline $30-400$ & 150 & $200-63$ & $200-63$ & 100 \\
\hline
\end{tabular}

AS can be seen from the table, company A and D use the fixed injection current at all frequency range, while $\mathrm{B}$ and $\mathrm{C}$ are exactly the same, both use different test severity in different frequency bands, up to $200 \mathrm{~mA}$.

\subsection{Sample Working State}

A requires that the battery pack be tested in the condition of discharge 30A.,while both $\mathrm{B}$ and $\mathrm{C}$ require that the discharge current should be in the case of $0.1 \mathrm{C}(3 \mathrm{~A})$. Company $\mathrm{D}$ demanded that the discharge circuit need to be connect the resistance load with 3A current discharge and fan duty ratio of $50 \%$. Company E has not made a clear request.

\subsection{Other Parameters}

All the company claim that the experiment must be carried out in a unmodulated and AM modulated mode, with a frequency of $1 \mathrm{KHz}$ and a modulation depth of $80 \%$ and the dwell time of each frequency point is at least 2 second.

In respect of frequency step sizes,company A in $1 \sim 10 \mathrm{MHz}, 10 \sim 200 \mathrm{MHz}, 200 \sim 400 \mathrm{MHz}$ is $1 \mathrm{MHz}, 5 \mathrm{MHz}, 10 \mathrm{MHz}$,respectively, while company $\mathrm{E}$ in $1-200,200-400$ is $1 \mathrm{MHz}, 5 \mathrm{MHz}$. The other three did not make any demands. 


\section{BCI Test}

\subsection{Normal Test of BCI}

In order to verify the immunity performance of the battery pack,we selected a well-known domestic manufacturers of battery packs for BCI test.The sample is energized to operate normally and the discharge current is 20A.The step size and dwell time is shown in table 3 . According to the test parameters in part 2 , we determine the test severity to be $150 \mathrm{~mA}$. The set-up reference standard of ISO11452-4:2011[3].The test will carried out without modulation. During the testing process,we monitor the CAN communication state, the relay state and the load,and found that the CAN communication is normal, message sending cycle is stable,the relay and the load is on the right track.

Table 3 Parameters of BCI test

\begin{tabular}{|c|c|c|}
\hline Frequency Band $(\mathrm{MHz})$ & Step size $(\mathrm{MHz})$ & Dwell time $(\mathrm{s})$ \\
\hline $1 \sim 10$ & 1 & 2 \\
\hline $10 \sim 200$ & 5 & 2 \\
\hline $200 \sim 400$ & 10 & 2 \\
\hline
\end{tabular}

\subsection{Novel Test of BCI}

Taking into account the actual operation of the vehicle, the battery pack is always in a discharge state. In this process, The battery pack will always be subject to electromagnetic interference. In order to simulate the actual vehicle operation process, $\mathrm{BCI}$ test for the battery pack is carried out during the battery pack discharging process,and, the upper computer software is used to monitor and record the total voltage, current, cell temperature and battery monomer voltage of the whole discharge process.

For the sake of comparison,First, the battery pack is discharged without BCI. The discharge current is $20 \mathrm{~A}$ and lasts 20 minutes. The other test parameters are the same as part3.1. The upper computer monitoring data of this process wii be saved after completion.Second, Charge the battery voltage to the value of before discharge, then place the current injection probe on the location of $150 \mathrm{~mm}$, set the test severity to $150 \mathrm{~mA}$ and Keep discharging for 20 minutes. Save the upper computer monitoring data when the test is finished.

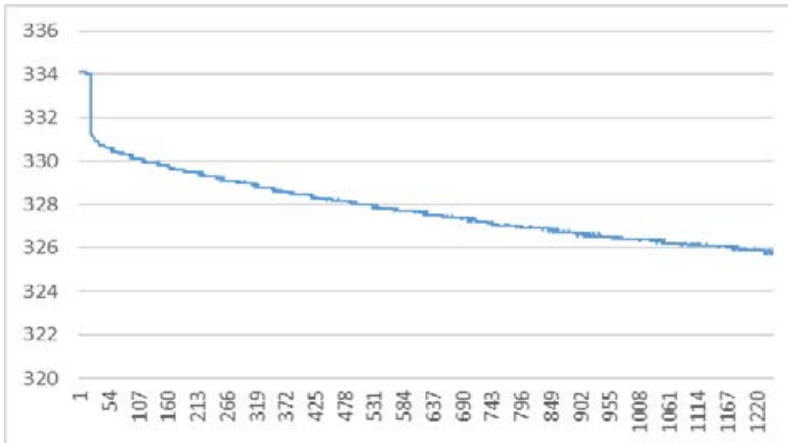

Fig. 1 voltage curve of battery pack without interference during discharge process

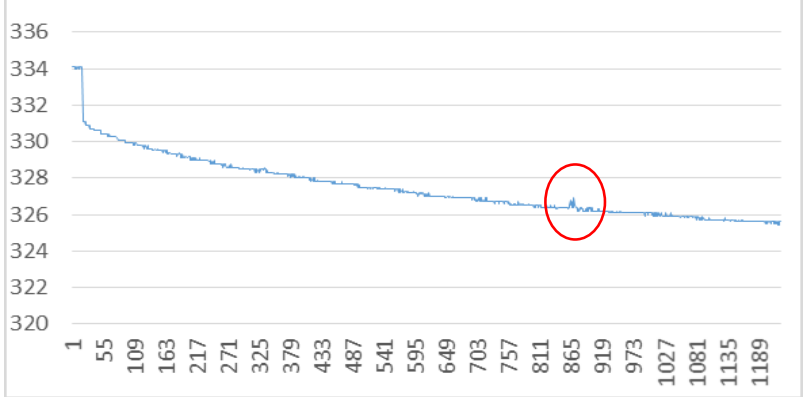

Fig. 2 voltage curve of battery pack with interference during discharge process

As we can seen from figure 1, the discharge curve of battery pack is very smooth without interference. And in the case of interference, as shown in figure 2, a bulge can be seen at coordinates 865. Observing the temperature curve, as shown in figure 3, can be found that in the absence of interference, the temperature in the discharge process only changes in the range of 19.4-19.5 While 
with BCI interference, as shown in figure 4, the temperature fluctuation is very obvious, especially in the middle of 477 and 545 points, the temperature of the individual points is shown to be 18.9 degrees, and the deviation is up to 0.6 degrees. The voltage and temperature collection of the battery management system is affected when the interference is exerted, and this is invisible only by observing the CAN communication interface and load state.and it can be assumed that BMS itself is affected by the injection current.Therefore, it is possible to consider the discharge process test with $\mathrm{BCI}$ in the later stage.

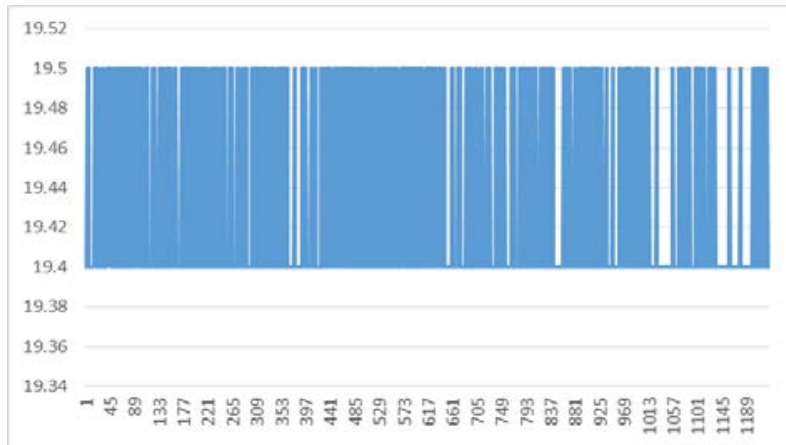

Fig. 3 temperature curve of battery pack without interference during discharge process

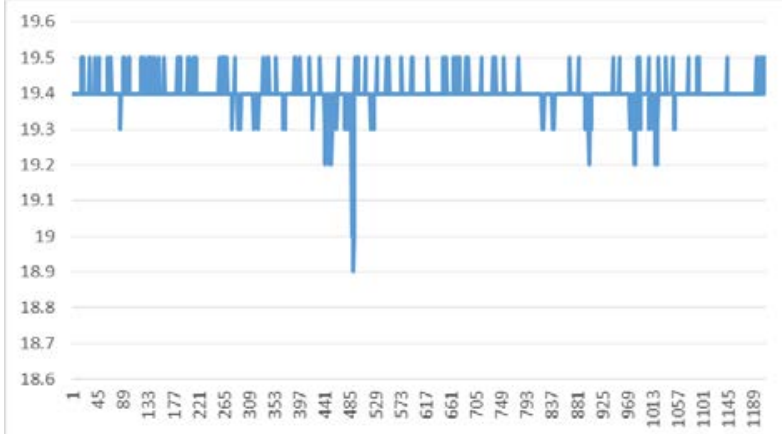

Fig. 4 temperature curve of battery pack with interference during discharge process

\section{Summary}

In this paper, BCI method of domestic famous battery pack manufacturers is compared and studied. Base on statistic information,we carried out a experniment with test severity level 150mA on a battery pack, as well a test with novel method which is using the upper computer software monitor and record the the data of the whole discharge process.It can be seen from the results that the detailed monitor data analysis of the discharge process with BCI is necessary.

\section{References}

[1] ISO 11452-4:2005 Road vehicles - Component test methods for electrical disturbances from narrowband radiated electromagnetic energy - Part 4: Bulk current injection (BCI),S.

[2] Yue M L. Research on Testing Difference between ISO 11452-4:2011 and ISO 11452-4:2005,J. Environmental Technology, 2012.

[3] ISO 11452-4:2011 Road vehicles - Component test methods for electrical disturbances from narrowband radiated electromagnetic energy - Part 4: Harness excitation methods,S. 